\title{
Understanding and Advancing the Health of Older Populations in sub-Saharan Africa: Policy Perspectives and Evidence Needs
}

\author{
Isabella Aboderin, $\mathrm{PhD}^{1}$
}

\begin{abstract}
Background: Debate on policy challenges associated with the health of older populations in sub-Saharan Africa (SSA) has intensified in recent years, centering on a concern about older persons' vulnerability to ill-health and their exclusion from health services. Despite international policy calls and formal expressions of commitment on the part of SSA governments, comprehensive policy action has remained scant. The impasse reflects a lack of political will and an uncertainty about required policy approaches, engendered by wide gaps in understanding of old age-related health in the region.

Purpose: The purpose of the paper is to pinpoint major approaches and areas of evidence needed as a priority to overcome the impasse in policy on ageing and health in SSA.

Methodology: A critical review of relevant SSA and international scientific, policy and development literature conducted as part of a research project on Dimensions and determinants of health in old age in Kenya and Nigeria: implications for policy. Results: Six major areas of evidence and a spectrum of approaches are required to (i) strengthen the case on why action on old age-related health should be pursued in the SSA setting and (ii) clarify what concrete forms such action should take.

Conclusion: A systematic research endeavour on the six areas is needed to advance policy and practice on the health of older populations in SSA. If accompanied by an explicit international comparative perspective such research also has the potential to significantly advance scientific debate on ageing and health globally.
\end{abstract}

Key Words: sub-Saharan Africa, aging, older adults, health policy

Recommended Citation: Aboderin I. Understanding and Advancing the Health of Older Populations in sub-Saharan Africa: Policy Perspectives and Evidence Needs. Public Health Reviews. 2010;32:357-76.

\footnotetext{
${ }^{1}$ Oxford Institute of Ageing, University of Oxford.
}

Corresponding Author Contact Information: Isabella Aboderin at isabella.aboderin@ ageing.ox.ac.uk; Oxford Institute of Ageing, University of Oxford, 66, Banbury Road, Oxford OX2 6PR, UK. 


\section{INTRODUCTION}

International debate on the policy challenges associated with the health of ageing populations in sub-Saharan Africa (SSA) has intensified in recent years, based on two key points of departure. The first are current demographic projections, which (though tenuous, given the absence of reliable vital registration systems in most SSA countries) ${ }^{1}$ show SSA to have the fastest growing older population of any world region. While the share of persons aged 60 and over* will remain much lower than elsewhere (increasing from presently 5 percent to only 9.1 percent by 2050), their absolute number will see the sharpest rises globally: from 42.6 million in 2010 to 160 million by $2050 .^{2}$ Second is SSA's status as the poorest and 'least developed' major world region, ${ }^{3,4}$ which implies that the ageing of its populations is largely unfolding in contexts of widespread economic strain. ${ }^{5}$

Against this backdrop, the discourse on challenges of ageing and health in SSA centres not, as it does in industrialized countries, on queries about expected trends in old age morbidity, mortality and disability and the sustainability of existing health and care systems. ${ }^{6-8}$ The focus, rather, are concerns about a heightened vulnerability of older persons to detrimental health outcomes - in two respects. On one level, older populations in SSA are deemed to be at particularly high risk of ill-health and disability from age-related chronic non-communicable disease (CNCD), due to a lifetime of exposure to conditions of deprivation and a growing prevalence of modifiable CNCD risk factors. ${ }^{5,9,12}$ On a second level, older persons are believed to lack access to even basic healthcare and, crucially, to have less access to services than do younger age-groups - suggesting an element of age-related exclusion. ${ }^{9,10,13}$

\section{POLICY CHALLENGES}

In response to the concerns, two recent international frameworks, the 2002 United Nations Madrid International Plan of Action on Ageing (MIPAA) ${ }^{9}$ and the 2003 African Union Policy Framework and Plan of Action on Ageing (AU-Plan), ${ }^{10}$ urge the development of strategies to enhance health service provision for Africa's older persons as a way to realize their right to health and to encourage their valuable contributions to families and societies. The Plans call for two main types of measures: (i) multi-faceted health promotion

\footnotetext{
* The United Nations' definition of 'old age' as 60 years and over is becoming increasingly entrenched in the international discourse. Readers should bear in mind the limitations of this definition, however, including its questionable appropriateness for African settings.
} 
strategies to prevent disease and disability among successive cohorts of older persons, and (ii) policies to ensure full access to adequate curative and rehabilitative care for older persons who already suffer from disease or disability. Such responses, as MIPAA and AU-Plan assert, are to be forged as part of core national health and development agendas and to serve the ultimate goal of enhancing older persons' quality of life. ${ }^{5}$ The recommendations overlap with intensifying calls on Africa's governments to prevent and manage their countries' rising burden of $\mathrm{CNCD}$, such as cardiovascular disease (CVD), chronic respiratory disease, diabetes and cancers, which overwhelmingly affect adults in their middle and older ages. . $^{12,14-18}$

As signatories to MIPAA and AU Plan and prompted by the calls on CNCD, SSA countries formally acknowledge the need for policy responses on old age-related health needs. Collectively, African governments propose action to address these needs in the African Union Africa Health Strategy 2007-2013. ${ }^{19}$ Individual states (including, for example, Burundi, Kenya, Nigeria, Senegal, South Africa and Tanzania) pledge relevant measures as part of national health sector plans and, in some cases, broader national policy frameworks on ageing. ${ }^{20,21}$ Typically, countries propose (to varying degrees of detail) one or both of two kinds of responses: (i) steps to develop preventive and/or curative primary healthcare services for major CNCD and, in some cases (e.g., Kenya) other degenerative diseases, ${ }^{22}$ and/or (ii) social protection measures to redress the exclusion of older persons (and other vulnerable groups) from health services, by removing financial barriers. Thus, Kenya's National Health Sector Strategic Plan II 2005-2012 (NHSSP II), for example, proposes:

"Various measures...to improve financial access to health services, specifically for the financially vulnerable and the very poor: the elderly, street children and orphans, single mothers, and patients with chronic diseases like TB, HIV/AIDS, diabetes, etc."22(p.12) (emphasis added)

\section{Impasse in National Policy}

However, despite countries' pledges, little comprehensive policy action has ensued. All indications are that SSA health services remain largely or partially unresponsive to old age-related health needs. This includes the few states - specifically Senegal and South Africa - that have implemented broad fee exemptions for older persons. ${ }^{* 1,23,24}$ The reasons for the policy

\footnotetext{
* Senegal's Plan Sesame policy, introduced in 2006, provides free healthcare access for all older persons aged 60+; while South Africa provides free healthcare for frail/disabled older persons and recipients of the Old Age Grant. ${ }^{20}$
} 
impasse have not yet been formally investigated. Despite the lack of investigation, recent joint analyses by health policy, practice and research stakeholders from several SSA countries point to three implicated factors: (i) obstructions to the enactment of drafted policies, as is the case, for example, with Nigeria's Revised National Health Policy (2004) and National Policy on Ageing (2008), (ii) loose policy formulation that is unable to guide detailed program design, and (iii) compromised implementation due to insufficient budget allocation or other capacity limitations. ${ }^{20,21}$ The three impediments are symptomatic of a persisting uncertainty of SSA policy makers and planners in two regards. First, is a lack of conviction that action on old age-related health should be a priority within a context of myriad pressing public health and development challenges. A seemingly typical stance of legislators and central planning or finance ministries is that national budgets have no capacity to sustain the realization of policies for older persons. Such policies, as opposed to programmes on essential health needs of children, youth and younger-age adults, are seen as an obstruction, or at best as irrelevant, to core national development interests. Second, decision makers lack clarity about what specific measures are needed to effectively ensure the health of older adults. An example are the provisions on older persons in Kenya's NHSSP II whose translation has been hindered, among others, by a lack of insight into what older persons' priority health needs are, and how health or other sectors could appropriately respond to them. ${ }^{5,20,21}$

What underlies the uncertainties are wide gaps in understanding of both (i) the scope, determinants and impacts of unmet old age-related health needs in SSA societies and (ii) the nature and causes of major deficiencies in service provision for them. To be sure, a fair body of research on the health of older persons in SSA has accumulated over the last decade, including, notably, the World Health Organization (WHO) Study on Adult Health and AGEing (SAGE) ${ }^{25}$ and the Ibadan Study of Ageing.

Intersecting with this is a considerable volume of work on aspects of CNCD in SSA populations. Together, the generated findings illuminate the contours of old age-related health challenges, i.e., namely:

(i) Sizeable proportions of older persons suffer from malnutrition, ${ }^{26,27}$ often multiple chronic physical and mental disease conditions (such as musculo-skeletal and cardiovascular conditions, impaired vision or hearing, depression and dementia) ${ }^{28-33}$ and consequent impaired health and function. ${ }^{34-40}$

(ii) Health and functional impairments may significantly impact on older persons' quality of life. ${ }^{41,42}$ 
(iii) Within the older population, levels of ill-health and impaired function clearly vary between sociodemographic (e.g., gender, rural/urban, socioeconomic) groups. ${ }^{28,29,34,37-40}$ Evidence suggests a consistently higher risk of disability, depression, dementia as well as self-reported poor health and function among older women compared to men. Findings on relationships of rural/urban and socioeconomic status to health outcomes, however, are less clear.

(iv) In adult populations as a whole, there is a considerable prevalence of CVD and diabetes and major CNCD risk factors, in particular hypertension, but also dyslipidemia, obesity, alcohol and tobacco use. .3-45 $^{-4}$

(v) The prevalence of CNCD and risk factors varies across countries as well as between sociodemographic groups. Clearly emerging patterns include a consistently higher prevalence of hypertension, as well as diabetes and obesity in urban compared to rural areas. ${ }^{43-45}$

(vi) Older persons and adults with CNCD often lack access to required curative, preventive or diagnostic health services. ${ }^{43-46}$

(vii) Older persons may have systematically less access to healthcare than younger age groups. ${ }^{47,48}$

Despite their importance, the insights generated thus far are unable to adequately fill the information gaps that have hindered progress in policy action on ageing and health in SSA countries.

\section{Overcoming the policy impasse: a need for research}

Overcoming the impasse will require a new systematic research effort to address the gaps. The need for such further inquiry has been clearly recognized in recent reviews, ${ }^{49}$ as well as the AU Plan and MIPAA, and the associated UN Research Agenda on Ageing for the $21^{\text {st }}$ century., ${ }^{9,10,50}$ However, the frameworks provide limited guidance on what particular evidence is required as a priority in SSA and what broad approaches should inform its generation. This includes an omission to underscore the basic importance of building synergy between inquiry on ageing and CNCD. The remainder of this paper provides perspectives on the kinds of evidence that are essential for advancing policy and practice on ageing and health in SSA. It does so based on a critical review of relevant scientific, policy and development literature conducted as part of a recent Wellcome Trust funded study on 'Dimensions and Determinants of Health in Old Age in Kenya and Nigeria: Implications for Policy'.

The two basic tasks for research are to generate information that can (i) strengthen the case on why SSA governments should address old agerelated health needs as a priority and (ii) clarify what forms such action 
should take. A starting point for pinpointing what evidence is needed for the first task, is to appreciate three health systems imperatives that SSA health policy makers will need to take into account when deciding on action, namely: (i) acute resource constraints, (ii) a priority focus on attaining the Millennium Development Goals (MDGs), and (iii) the objective of achieving equity in healthcare.

\section{Acute resource constraints}

SSA's public health sectors face acute resource pressures, which follow decades of underinvestment and are compounded by a 'triple burden' of persisting infectious and rising chronic disease as well as injury and trauma. ${ }^{19,23}$ Despite government and donor pledges to increase health spending, national health services remain limited by major shortfalls in infrastructural, financial, medical and/or human capacity. ${ }^{23,51}$

\section{Priority focus on Millennium Development Goals}

Within the context of constrained resources, SSA health sector strategies give priority to the provision of services to achieve the health-related MDGs 4, 5 and 6 - that is, to reduce the rates of child and maternal mortality, HIV/AIDS, malaria and tuberculosis (TB) (for all of which SSA has the highest rates globally). ${ }^{52}$ In so doing, the strategies form an integral part of countries' overall Poverty Reduction Strategies (PRS), ${ }^{*}$ which seek to attain all eight MDGs. ${ }^{53,54}$ Kenya's NHSSP II, for example, states:

\footnotetext{
${ }^{*}$ PRS are central to present development efforts in most SSA countries. ${ }^{53}$ They go by different names such as the 'Economic Recovery Strategy for Wealth and Employment Creation (ERSWEC) in Kenya' or the 'National Economic Empowerment and Development Strategy (NEEDS)' in Nigeria. Each strategy stipulates a framework for macroeconomic, structural and social policies that a respective country will pursue, ultimately, to achieve the MDGs. The eight MDGs and their associated targets, as set out in the UN Millennium Declaration, ${ }^{76}$ form the core of the international community's development agenda for poor world regions, including SSA. The targets, to be achieved by 2015 , are to:

1.Halve the proportion of people whose income is less than \$1 USD a day and the proportion that suffers from hunger.

2.Attain universal primary education in all countries.

3.Eliminate gender disparity in primary and secondary education and at all levels of education.

4.Reduce mortality by two-thirds among children younger than five years.

5.Reduce the maternal mortality ratio by three-quarters.

6.Halt and begin to reverse the spread of HIV/AIDS, and the incidence of malaria and other major diseases.

7.Halve the proportion of people without access to safe drinking water, and by 2020, achieve significant improvement in the lives of at least 100 million slum dwellers.

8.Develop a global partnership for development.
} 
"The Government of Kenya is determined to...ensure that the health sector plays its essential role in the realization of the Kenyan Economic Recovery Strategy for Wealth and Employment Creation (ERS)... As a signatory of the Millennium Declaration with its internationally defined Millennium Development Goals (MDGs), Kenya has expressed its commitment to reach these targets in the remaining ten years... The NHSSP II is an integral part of ERS, from which it is derived."22(p.5)

The preference given to services for maternal and child health, malaria, TB and HIV/AIDS is reinforced by the often heavy reliance of SSA health systems on donor aid - which is overwhelmingly earmarked for MDGrelated programmes..$^{54}$

\section{Equity in healthcare as a major objective}

In addition to a focus on the MDGs, SSA health sector strategies and many overarching national development plans assert a fundamental objective of achieving equity in healthcare. For example, Nigeria's revised national health policy is directly based on:

"The principle of social justice and equity and...ideals of freedom and opportunity" and the goal of "equity in health care and in health for all Nigerians." $55($ p.4)

The emphasis on equity reflects growing international recognition of its importance as a prerequisite not only for social justice but also for effective development. ${ }^{56,57}$ The equity perspective, together with health systems' resource constraints and a core emphasis on the MDGs points to three principal kinds of evidence that are needed to reinforce the argument on why policy action on old age-related health should be pursued.

\section{CHALLENGES FOR RESEARCH I: STRENGTHENING THE CASE FOR ACTION}

\section{Magnitude of the problem}

A first area of evidence required to strengthen the case for action is data to quantify the extent of the 'problem' of old age-related ill-health in individual countries - both in absolute and relative terms. National indices and regional league tables are needed on (i) the prevalence of $\mathrm{CNCD}$, disability, and CNCD risk factors in the middle - and older aged population and (ii) levels of basic service provision for them, together with data on the share of national health service loads caused by such conditions. Such evidence 
will likely raise political will to act on old age-related health - just as SSA governments are spurred to action on maternal, child health and major infectious diseases by regular publication (for example in Human Development, or MDG reports) of country-level data and rankings of mortality rates from, and service provision for, these conditions. In a few countries, useful data to furnish initial national indicators are being generated by monitoring surveys such as those using the WHO STEPS approach to (i) risk factor and/or (ii) stroke surveillance, ${ }^{58}$ and/or are expected to emerge from completed studies from SAGE. Further primary data generation is inevitable, however, and should build on an expansion of WHO STEPS and of regular surveys (such as Demographic and Health Surveys, or Multiple Indicator Cluster Surveys) already undertaken by most SSA countries to monitor core development and health trends.

A prerequisite for such efforts is a refinement of currently available survey measures of health in SSA adult populations. Focus is required on shortcomings of commonly used (i) self-reporting indicators of disease, (ii) self-ratings of symptoms or function, and (iii) quality of life (QOL) scales. The first two measures presuppose knowledge that respondents could only derive from their own health literacy or formal diagnoses by medical services. Both are far from given in SSA settings, especially among older, rural, or poor adults. Items requiring respondents' self-ratings of symptoms or levels of function - as for example in SAGE 'health state descriptions' or Instrumental Activities of Daily Living (IADL) scales, can be limited in two respects. First, queried functions, such as, for example, difficulty with climbing stairs or concentrating on a task for 10 minutes, may be neither meaningful nor elicit accurate information in rural or illiterate older populations. Second, while respondent ratings may capture actual health states among literate older adults in countries with advanced health systems,${ }^{59}$ their effectiveness remains less clear for older persons in SSA contexts, who may have very different conceptions of health and function in old age as well as of 'complaints' about them. Unfortunately, we know very little about such conceptions at present. Thus, while some advances are being made with the use of anchoring vignettes as in the WHO SAGE study, careful qualitative work - as well as triangulation with health examination and biomarker data - is required to illuminate meanings and relevance of older adults' evaluations of their health and function in SSA settings.

\section{Impacts on progress towards achieving the MDGs}

A second kind of evidence necessary to bolster the case for action on old age-related ill-health and disability, is careful documentation of the extent 
to which such conditions impact negatively on countries' social and economic development - in particular on progress toward achieving the MDGs. Analysis should consider MDG-related areas, such as child wellbeing, HIV/AIDS and economic productivity broadly, to which middle aged and older persons in SSA are known to contribute substantially, by virtue of their intergenerational and economic roles in families and communities. ${ }^{5,60,61}$ Research in this area may usefully build on approaches being developed for assessing the broad economic costs or socioeconomic consequences of CNDC. . $^{17,62}$

\section{Age-related inequities in healthcare access}

A final, critical kind of evidence needed to raise political will to act on older persons' health is firm data on the extent to which older persons indeed have systematically less access to healthcare than do younger agegroups. A latent potential for such age-related access inequities certainly exists within a health systems context that combines acute resource constraints with a categorical priority focus on developing services for younger, MDG-related groups (children, mothers, malaria, TB and AIDS sufferers). However, no robust evidence exists thus far of possible agerelated disparities in healthcare access. Similarly, (old) age has been largely overlooked as a potentially important factor in the intensifying debate on access inequities. ${ }^{63,64}$ Perhaps tellingly it is also omitted in the conceptual framework of the WHO Commission on Social Determinants of Health. ${ }^{57}$ Studies to date have focused mainly on household-level disparities by socioeconomic or rural/urban status ${ }^{65-68}$ or individual- (including intrahousehold-) level differences by gender or children's age. ${ }^{69-72}$ With one or two exceptions, ${ }^{47,71}$ no research has directly examined the role of (old) age as a determinant of differential healthcare access. Efforts to illuminate potential age-related access inequities ought ideally to build on three types of evidence. First are nationally representative data on patterns of health service utilization and receipt of appropriate care for existing need in the older compared to younger age population. Second are health systems analyses to establish the relative availability (and, where appropriate, affordability) of basic services (diagnostic tests, medicines, equipment, skilled staff) for old age-related conditions, compared to service provision for essential health needs of younger age groups. Third are qualitative explorations of key factors shaping relative service utilization and care receipt among young and old within households and families. Drawing on recent conceptual developments regarding social exclusion in old age, globalization and social determinants of health, ${ }^{73-75}$ any identified age-related 
disparities in care access can then be explicated in terms of major individual/ family, local-, national- and global-level factors that give rise to them.

\section{CHALLENGES FOR RESEARCH II: 'CLARIFYING APPROACHES'}

Having strengthened the case for action on old age-related health, research is needed to clarify what practical approaches are likely to be most effective and appropriate for (i) enhancing access to care for old age-related illhealth and (ii) preventing the development of such conditions in the first place. Two key areas require investigation to this end.

\section{Determinants of access to healthcare}

First, is the development of a sound understanding of major demand - and 'supply-side' factors at micro and macro levels that presently combine to impede access to adequate care for older persons and those with CNCD. Indications of some of these factors are provided by a number of small scale, qualitative studies on care seeking among older people or diabetes sufferers, ${ }^{46,76,77}$ analyses of the availability and cost of essential CNCD drugs ${ }^{78,79}$ and general examinations of impacts of user fee or quality changes on health service utilization in SSA countries. ${ }^{64,80-83}$ The findings point to negative impacts of physical and logistical access difficulties, financial barriers related to service fees and/or transport costs and a perceived lack of quality (or unavailability altogether) of requisite services in the public sector. Beyond this, however, no systematic, country-level evidence exists.

Although some recent SSA health systems and policy research has sought to examine determinants of healthcare utilization in detail, the focus has been on MDG-related service areas, specifically malaria, HIV/TB, and maternal and child care. ${ }^{84-86}$ Similar investigations on care services for old age-related ill health are urgently needed. The 'Health Access and Livelihood' framework ${ }^{63}$ provides a useful starting point for and can be further refined by such research.

\section{Social determinants of health at older ages}

The major evidence required for identifying apposite strategies to prevent ill health and disability in older ages is an understanding of the social mechanisms that act over the life course to engender them. The direct behavioral and biological CNCD risk factors are, of course, well recognized. ${ }^{15}$ Much less is known, however, about the social processes and causal 
pathways that give rise to them in SSA settings. As mentioned above, several studies have explored basic social patterns of specific diseases or of health and function broadly in older SSA adult populations. They suggest an apparent disadvantage of women, but thus far provide no consistent evidence on variations by socioeconomic or rural/urban status. Moreover, and in contrast to burgeoning research in the developed world, Latin America and Asia, ${ }^{57,87-91}$ there has been very little further investigation of the social determinants of CNCD and health at older ages in Africa. Such inquiry needs to be fostered and should actively examine the relevance for SSA of theoretical and empirical insights generated by research in other world regions. Such notions regard (i) timing and effects of impacts ${ }^{88}$ including ideas about an accumulation of social and health (dis)advantage over the life course $^{92}$ and (ii) key social exposures negatively shaping adult health, such as direct impacts of work ${ }^{93}$; material deprivation ${ }^{57}$; stress, lack of control and unhappiness ${ }^{94}$; lack of social support ${ }^{95}$; and infectious disease. ${ }^{96}$

A most immediate need, however, is for enhanced research on the social correlates of health and disease in older adult populations in SSA. A prerequisite for this (in addition to refining measures of health status as discussed above) is the forging of more incisive indicators of rural/urban, economic and social status than currently exist.

\section{Measures of Rural/Urban Status}

As others have noted, ${ }^{97}$ there is a need to move beyond current simple comparisons of rural and urban residents, to accurately capture individuals' lifetime exposure to urban or rural environments. Major issues to be considered in this respect include, first, difficulties of obtaining accurate chronological recall of previous life phases, including birth dates, due to a widespread lack of formal education and birth certificates among current older cohorts in the SSA context. This may be tackled through the use of prompts on locally relevant historical events ${ }^{98}$ and a focus on broad life stages (early childhood, adolescence, early adulthood, middle age, old age). Second are frequent country and time period variations in the classification criteria used to define 'rural' and 'urban' areas in surveys. These necessitate careful reflection on the ways in which particular criteria relate to key exposures ascribed to rural and urban contexts. Last is the importance of distinguishing exposures to urban environments resulting from in-migration as opposed to urbanization of a previously 'rural' place of residence - as impacts on health will likely be different. ${ }^{97}$ 


\section{Measures of Economic Status}

Improving measurement of economic status of (older) adults in SSA requires the development of sound individual-level indicators to replace presently used household-based markers such as wealth indices based on household assets, per capita income or expenditure. Besides general doubts about the value of income and assets as gauges of household economic well-being in SSA settings, ${ }^{99,100}$ such indicators overlook the critical factor of how resources are allocated between individual household members. ${ }^{5}$ Subjective measures of individual economic well-being, as employed in recent United States and Latin American research, ${ }^{101-103}$ may be useful alternatives and should be explored. In addition, there is a need for retrospective indicators, as developed for example in the SHARELIFE study conducted in Europe, which can capture earlier life economic wellbeing of middle-aged or older adults.

\section{Measures of Social Status}

Thus far, social status has received little, if any, active consideration in investigations on the social patterns of health in older ages in SSA. The significance of this omission is indicated by evidence from the developed world of a clear link between lower social status and worse health outcomes, mediated by maladaptive chronic stress responses and/or risk behaviors and engendered by feelings of lack of control, insecurity, hopelessness or hostility. ${ }^{94,104}$ One may reasonably assume that similar processes also play a role in shaping (older) adults' health in SSA societies - and their investigation is imperative. However, measures of social status, based on occupational and educational class as used in industrialized countries, ${ }^{88}$ are unlikely to be suitable for this purpose, given a broad lack of formal education especially among older cohorts, and the predominance of informal, unstructured labor markets in SSA. Development of appropriate indicators of social status should be a priority and must begin with qualitative explorations of the criteria through which social hierarchies and prestige in earlier and later adult life are constructed in African settings.

\section{SUMMARY AND CONCLUDING REMARKS}

This paper has described the present impasse in policy action on ageing and health in SSA and pinpointed major impediments underlying it - namely a lack of political will and/or clarity about what concrete programs to fashion, which largely reflect decision makers' dearth of understanding of the scope, 
determinants and impacts of old age-related health needs. Building on an appreciation of the present health systems context in SSA, the paper delineates five areas of evidence needed to (a) strengthen the case for action on the health of older populations and (b) clarify what forms it should take - namely (i) the magnitude of the problem, (ii) its impacts on progress towards the MDGs, (iii) the possible existence of age-related inequities in healthcare access, (iv) determinants of access to healthcare, and (v) social determinants of health and function at older ages. Systematic research on the five areas will carry a real potential to advance policy and practice in SSA - especially if complemented by rigorous evaluations ${ }^{80}$ of the effectiveness of existing programmes designed to improve healthcare utilization or CNCD prevention or management among older SSA populations. Beyond a potential policy impact, SSA research on the above areas can serve to advance scientific debate on issues of ageing and health globally - in particular if analyses embrace a comparative international perspective. A first step towards the fostering of such a perspective is increased exchange and joint reflection between SSA scholars and those working on other world regions. This paper hopes to contribute to this.

\section{Acronyms list:}

$\mathrm{CNCD}=$ chronic non-communicable disease

MDGs $=$ Millennium Development Goals

SAGE $=$ WHO Study on global AGEing and adult health

SSA $=$ sub-Saharan Africa

Acknowledgements: Funding for the research project 'Dimensions and determinants of health in old age in Kenya and Nigeria: implications for Policy' was provided by the Wellcome Trust, Grant No: WT WT078866MA)

Conflicts of Interest: None declared.

\section{REFERENCES}

1. Velkoff VA, Kowal PR. Population ageing in sub-Saharan Africa: Demographic dimensions 2006. U.S. Census Bureau, Current Population Reports, P 95/071. Washington (DC): U.S. Government Printing office; 2007.

2. United Nations Population Division. World population prospects: the 2008 revision. 2010. Available from URL: http://esa.un.org/unpp/ (Accessed 6 January 2010).

3. World Bank. Country classification. 2010. Available from URL: http:// go.worldbank.org/K2CKM78CC0 (Accessed 4 January 2010).

4. United Nations Development Programme. Human development report 2010. The real wealth of nations. Pathways to human development. New York (NY): Palgrave Macmillan; 2010. 
5. Aboderin I, Ferreira M. Linking ageing to development agendas in sub-Saharan Africa: Challenges and approaches. J Popul Ageing. 2009;1:51-73.

6. Ofstedal MB, Zimmer Z, Hermalin A, Chan A, Chuang YL, Natividad J, Tang Z. Short-term trends in functional limitation and disability among older Asians: A comparison of five Asian settings. J Cross Cult Gerontol. 2007;22:243-61.

7. Robine JM, Michel JP. Looking forward to a general theory on population aging. J Gerontol Med Sci. 2004;59A:590-7.

8. Martin LG, Freedman VA, Schoeni RF, Andreski PM. Trends in disability and related chronic conditions among people aged fifty to sixty-four. Health Affairs. 2010;29:725-31.

9. United Nations. Madrid International Plan of Action on Ageing (MIPAA). New York (NY): United Nations; 2002.

10. African Union/HelpAge International. Policy framework and plan of action on ageing. Nairobi: HAI Africa Regional Development Centre; 2003.

11. Kalache A, Aboderin I, Hoskins I. Compression of morbidity and active ageing: Key priorities for public health policy. Bull World Health Organ. 2002;80:243-4.

12. Daar AS, Singer PA, Persad DL, Pramming SK, Matthews DR, Beaglehole R, et al. Grand challenges in chronic non-communicable diseases. Nature. 2007;450:494-6.

13. Lloyd-Sherlock P. Population ageing and development. From generalisation to evidence. Bristol (UK): Policy Press; 2010.

14. Amuyunzu-Nyamongo M. Need for a multi-factorial, multi-sectorial and multidisciplinary approach to NCD prevention and control in Africa. Glob Health Promot. 2010;1757-9759; Suppl: 31-2.

15. World Health Organization. 2008-2013 Action plan for the global strategy on the prevention and management of noncommunicable disease. Geneva: WHO; 2008.

16. Ebrahim S. Chronic diseases and calls to action. Int J Epidemiol. 2008;37:225-30.

17. World Bank. Public policy and the challenge of noncommunicable diseases. Washington (DC): World Bank; 2007.

18. De-Graft Aikins A, Unwin N, Agyemang C, Allotey P, Campbell C, Arhinful D. Tackling Africa's chronic disease burden: From the local to the global. Global Health. 2010;6:5.

19. African Union. Africa health strategy 2007-2013. Addis Ababa: African Union; 2007.

20. Aboderin I, Gachuhi, M. First East African policy-research dialogue on ageing. Identifying information gaps. AFRAN Policy-Research Dialogue Series, Report 01-2007. African Research on Ageing Network. Oxford Institute of Ageing; 2007.

21. Aboderin I. Advancing health service provision for older persons and agerelated non-communicable disease in sub-Saharan Africa: Identifying key information and training needs. AFRAN Policy-Research Dialogue Series, Report 01-2008. Oxford Institute of Ageing; 2008.

22. Kenya Ministry of Health. National Health Sector Strategic Plan II 2005-2012. Nairobi, Kenya: KMoH; 2005 
23. World Health Organization. The health of the people. The African regional health report. Brazzaville: WHO Regional Office for Africa; 2006.

24. Clausen T, Wilson AO. Twenty-five years of expectation. Where are the services for older people with mental illness in Africa? Int Psychiat. 2010;7:32-4.

25. Kowal P, Kahn K, Ng N, Naidoo N. et al. Ageing and adult health status in eight lower-income countries: the INDEPTH WHO-SAGE Collaboration. Global Health Action. 2010:Suppl2;11-22.

26. Kimokoti RW, Hamer DH. Nutrition, health and aging in sub-Saharan Africa. Nutr Rev. 2008;66:611-23.

27. Clausen T, Charlton KE, Holmboe-Ottesen G. Nutritional status, tobacco use and alcohol consumption of older persons in Botswana. J Nutr Health Aging. 2006;10:104-10.

28. Gureje O, Kola L Afolabi E. Epidemiology of major depressive disorder in elderly Nigerians in the Ibadan Study of Ageing: A community-based survey. Lancet. 2007;370:9591:957-64.

29. Clausen T, Romoren TI, Ferreira M, Kristensen P, Ingstad B, Holmboe-Ottensen G. Chronic diseases and health inequalities in older persons in Botswana (Southern Africa): A national survey. J Nutr Health Aging. 2005;9: 455-61.

30. Bekibele CO, Gureje O. Self-reported visual impairment and impact on visionrelated activities in an elderly Nigerian population: Report from the Ibadan Study of Ageing. Ophthalmic Epidemiol. 2008;15:250-6.

31. Bekibele CO, Gureje O. Fall incidence in a population of elderly persons in Nigeria. Gerontol. 2010;56:278-83.

32. Lasisi AO, Abiona T, Gureje O. The prevalence and correlates of self-reported hearing impairment in the Ibadan Study of Ageing. Trans R Soc Trop Med Hyg. 2010;104:518-23.

33. Gureje O, Ogunniyi A, Kola L. The profile and impact of probable dementia in a sub-Saharan African community: Results from the Ibadan Study of Aging. J Psychosom Res. 2006;61:327-33.

34. Gureje, O, Ogunniyi A, Kola L, Afolabi E. Functional disability in elderly Nigerians: Results from the Ibadan Study of Ageing. J Am Geriatr Soc. 2006;54:1784-9.

35. Clausen T, Wilson AO, Molebatsi RM, Holmboe-Ottesen G. Diminished mental- and physical function and lack of social support are associated with shorter survival in community dwelling older persons of Botswana BMC Public Health. 2007;7:144-52.

36. Gureje O, Ademola A, Olley BO. Depression and disability: Comparisons with common physical conditions in the Ibadan Study of Aging. J Am Geriatr Soc. 2008;56:2033-8.

37. Kyobutung C, Egondi T, Ezeh A. The health and well-being of older people in Nairobi's slums. Glob Health Action. 2010;S2:45-53.

38. Debpuur C, Welaga P, Wak G, Hodgson A. Self-reported health and functional limitations among older people in the Kassena-Nankana District, Ghana. Glob Health Action. 2010;S2:54-63. 
39. Gómez-Olivé, FX, Thorogood M, Clark BD, Kahn K, Tollman S. Assessing health and well-being among older people in rural South Africa. Glob Health Action. 2010;S2:23-35.

40. Mwanyangala MA, Mayombana C, Urassa H, Charles J, Mahutanga C, Abdullah S, Nathan R. Health status and quality of life among older adults in rural Tanzania. Glob Health Action. 2010;S2:36-44.

41. Gureje O, Kola L, Afolabi E, Olley BO. Determinants of quality of life of elderly Nigerians: Results from the Ibadan Study of Ageing. Afr J Med Med Sci. 2008;37:239-47.

42. Bekibele CO. Gureje O. Impact of self-reported visual impairment on quality of life in the Ibadan Study of Ageing. Br J Ophthalmol. 2008;92:612-5.

43. BeLue R, Okoror TA, Iwelunmor J, Taylor KD, Degboe AN, Agyemang C, Ogedegbe G. An overview of cardiovascular risk factor burden in subSaharan African countries: A socio-cultural perspective. Global Health. 2009;5:10-22.

44. Mbanya J-CN, Motala AA, Sobngwi E, Assah FK, Enoru ST. Diabetes in subSaharan Africa. Lancet. 2010;375:2254-66.

45. Addo J, Smeeth L, Leon DA. Hypertension in sub-Saharan Africa. A systematic review. Hypertension. 2007;50:1012-8.

46. Uwakwe R, Ibeh CC, Modebe AI, Bo E, Ezeama N, Njelita I, et al. The epidemiology of dependence in older people in Nigeria: Prevalence, determinants, informal care, and health service utilization. A 10/66 Dementia Research Group cross-sectional survey. J Am Geriatr Soc. 2009;57:1620-7.

47. McIntyre D. Health policy and older people in Africa. In: Lloyd-Sherlock P, editor. Living longer. Ageing, development and social protection. London and New York: Zed Books; 2004. p. 160-183.

48. Xu K, Evans DB, Kadama P, Nabyonga J, Ogwal PO, Nabukhonzo P, Aguilar AM. Understanding the impact of eliminating user fees: Utilization and catastrophic health expenditures in Uganda. Soc Sci Med. 2006;62:866-76.

49. Cohen B, Menken J. Report - Aging in sub-Saharan Africa: Recommendations for furthering research. In: Cohen B, Menken J, editors. Aging in sub-Saharan Africa: Recommendations for furthering research. Washington (DC): The National Academies Press; 2006. p. 7-45.

50. United Nations/International Association of Gerontology and Geriatrics. Research agenda on ageing for the 21st century. New York (NY): United Nations; 2008.

51. World Health Organization. World health statistics 2009. Geneva: WHO; 2009.

52. United Nations. Millennium Development Goals. 2010. Available from URL: http://www.un.org/millenniumgoals/ (Accessed 19 December 2009).

53. International Monetary Fund. Factsheet. Poverty Reduction Strategy Papers (PRSP). 2009. Available from URL: www.imf.org/external/np/exr/facts/pdf/ prsp.pdf (Accessed 8 January 2010).

54. African Development Bank. African development report 2006. Aid, debt relief and development in africa. Oxford (UK): Oxford University Press; 2006. 
55. Nigeria Federal Ministry of Health. Revised national health policy. Abuja, Nigeria: Federal Ministry of Health; 2005.

56. World Bank. World development report 2006: Equity and development. Washington (DC): World Bank; 2005.

57. World Health Organization. closing the gap in a generation: Health equity through action on the social determinants of health. Final Report of the Commission on Social Determinants of Health. Geneva: WHO; 2008.

58. World Health Organization. WHO STEP wise approach to surveillance. 2010. Available from URL: http://www.who.int/chp/steps/en/ (Accessed 20 April 2010).

59. Kuhn R, Rahman O, Menken J. Survey measures of health: How well do selfreported and observed indicators measure health and predict mortality. In: Cohen B, Menken J, Editors. Aging in sub-Saharan Africa: Recommendations for furthering research. Washington (DC): The National Academies Press; 2006. p. 314-342.

60. Ahenkora K. The contribution of older people to development. The Ghana study. Ghana, Accra: HelpAge International and HelpAge; 1999.

61. Mohatle T, deGraft Agyarko R. The contribution of older people to development. The South Africa study. UK: HelpAge International; 1999.

62. World Health Organization. WHO guide to identifying the economic consequences of disease and injury. 2009. Geneva: WHO. Available from URL: http://www.who.int/choice/publications/discussion_papers/en/index. html (Accessed 4 June 2010).

63. Obrist B, Iteba N, Lengeler C, Makemba A, Mshana C, Nathan R, et al. Access to health care in contexts of livelihood insecurity: A framework for analysis and action. PLoS Med. 2007;4:1584-8.

64. Gilson L, McIntyre D. Removing user fees for primary care in Africa: The need for careful action. BMJ. 2005;331:762-5.

65. Kristiansson C, Gotuzzo E, Rodriguez H, Bartoloni A, Strohmeyer M, Tomson G, Hartvig P. Access to health care in relation to socioeconomic status in the Amazonian area of Peru. Int J Equity Health. 2009;8:11.

66. Larson 1CP, Unnati RS, Rafiqul I, Nikhil R. Childhood diarrhoea management practices in Bangladesh: Private sector dominance and continued inequities in care. Int J Epidemiol. 2006;35:1430-9.

67. Chuma J, Gilson L, Molyneux C. Treatment seeking behaviour, cost burdens and coping strategies among rural and urban households in coastal Kenya: An equity analysis. Trop Med Int Health. 2007;12:673-86.

68. Rispel LC, de Sousa CA, Molomo BG. Can social inclusion policies reduce health inequalities in sub-Saharan Africa? A rapid policy appraisal. J Health Popul Nutr. 2009;27:492-504.

69. Guarnizo-Herreño CC, Agudelo C. Gender-related equity/inequity in gaining access to health services. Rev Salud Publica (Bogota). 2008;10Suppl:44-57.

70. Pokhrel S, Snow R, Dong H, Hidayat B, Flessa S, Sauerborn R. Gender role and child health care utilization in Nepal. Health Policy. 2005;74:100-9. 
71. Sauerborn R, Berman P, Nougtara A. Age bias but no gender bias in the intrahousehold resource allocation for health care in rural Burkina Faso. Health Transit Rev. 1996;6:131-45.

72. Larme, A. (1997) Health Care Allocation and Selective Neglect in Rural Peru Social Science and Medicine 44: 1711-1723.

73. Phillipson C. Aging and globalization: Issues for critical gerontology and political economy. In: Baars J, Dannefer D, Phillipson C, Walker A, Editors. Aging, globalization and inequality. Amityville (NY): Baywood; 2006. p. 43-58.

74. Scharf T, Phillipson C, Kingston P, Smith AE. Social exclusion and older people: Exploring the connections. Educat Ageing. 2001;16:303-20.

75. Labonté R, Schrecker T. Globalization and social determinants of health: Introduction and methodological background (Part 1 of 3) Global Health. 2007;3:5-15.

76. de Graft Aikins A. Healer-Shopping I Africa: New evidence from a rural-urban qualitative study of Ghanaian diabetes experiences. BMJ. 2005;331:737.

77. Kolling M, Winkley K, von Deden M. 'For someone who's rich it's not a problem'. Insights from Tanzania on diabetes health-seeking and medical pluralism among Dar es Salaam's urban poor. Global Health. 2010;6:8.

78. Mendis S, Fukino K, Cameron A, Laing R, Filipe A Jr, Khatib O, et al. The availability and affordability of selected essential medicines for chronic diseases in six low- and middle-income countries. Bull World Health Org. 2007;85:279-88.

79. van Mourik MSM, Cameron A, Ewen M, Laing RO. Availability, price and affordability of cardiovascular medicines: a comparison across 36 countries using WHO/HAI data. BMC Cardiovasc Disord. 2010;10:25.

80. Lagarde M, Palmer N. The impact of user fees on health service utilization in low- and middle-income countries: How strong is the evidence? Bull World Health Org. 2008;86:839-48.

81. Chuma J, Musimbi J, Okungu V, Goodman C, Molyneux C. Reducing user fees for primary health care in Kenya: Policy on paper or policy in practice? Int J Equity Health. 2009;8:15.

82. Bakeera SK, Wamala SP, Galea S, State A, Peterson S, Pariyo GW. Community perceptions and factors influencing utilization of health services in Uganda. Int J Equity Health. 2009;8:25-37.

83. Chawla M, Ellis RP. The impact of financing and quality changes on health care demand in Niger. Health Policy Plan. 2000;15:76-84.

84. Dillip A, Hetzel MW, Gosoniu D, Kessy F, Lengeler C, Mayumana I, et al. Socio-cultural factors explaining timely and appropriate use of health facilities for Degedege in south-eastern Tanzania Malar J. 2009;8:144.

85. Chibwana AI, Mathanga DP, Chinkhumba J, Campbell CH Jr. Socio-cultural predictors of health-seeking behaviour for febrile under-five children in Mwanza-Neno District, Malawi. Malar J. 2009;8:219.

86. Hetzel M, Iteba N, Makemba A, Mshana C, Lengeler C, et al. (2007) Understanding and improving access to prompt and effective malaria treatment and care in rural Tanzania. The ACCESS Programme. Malar J. 2007;6:83-98. 
87. Siegrist J, Marmot M, Editors. Social inequalities in health: New evidence and policy implications. Oxford (UK): Oxford University Press; 2007.

88. McMunn A, Breeze E, Goodman A, Nazroo J, Oldfield Z. Social determinants of health in old age. In: Marmot M, Wilkinson RG, editors. Social determinants of health. Oxford (UK): Oxford University Press; 2006. p. 267-96.

89. Smith K, Golman N. Socioeconomic differences in health among older adults in Mexico. Soc Sci Med. 2007;65:1372-85.

90. Nguyen CT, Couture M-C, Alvarado BE, Zunzunegui M-V. Life course socioeconomic disadvantage and cognitive function among the elderly population of seven capitals in Latin America and the Caribbean. J Aging Health. 2008;20:347-62.

91. Zimmer Z. Poverty, wealth inequality and health among older adults in rural Cambodia. Soc Sci Med. 2008;66: 57-71.

92. Ferraro K, Shippee TP. Aging and cumulative inequality: How does inequality get under the skin? Gerontologist. 2009;49:333-43.

93. Crystal S. Dynamics of late-life inequality: Modeling the interplay of health disparities, economic resources and public policies. In: Baars J, Dannefer D, Phillipson C, Walker A, Editors. Aging, globalization and inequality. The new critical gerontology. Amityville (NY): Baywood; 2006. p. 205-14.

94. Brunner E, Marmot MG. Social organization, stress and health. In: Marmot M, Wilkinson RG, (Editors). Social determinants of health. Oxford: Oxford University Press; 2006. p. 6-31.

95. Stansfield SA. Social Support and Social Cohesion. In: Marmot M, Wilkinson RG, (Editors). Social determinants of health. Oxford: Oxford University Press; 2006. p. 148-171.

96. Monteverde M, Noronha K, Palloni A. Effect of early conditions on disability among the elderly in Latin America and the Caribbean. Popul Stud. 2009;63:21-35.

97. Kinra S. Commentary: Beyond rural-urban comparisons: Towards a life course approach to understanding health effects of urbanization. Int J Epidemiol 2004;33:777-8.

98. Ogunniyi AO, Osuntokun BO. Determination of ages of elderly Nigerians through historical events: Validation of Ajayi-Igun. West Afr J Med. 1993;12:189-90.

99. Falkingham J, Namazie C. Measuring health and poverty. A review of approaches to identifying the poor. London (UK): DFID Health Systems Resource Centre, Department for International Development (DFID); 2002.

100. Expert Group on Poverty Statistics (Rio Group). Compendium of best practices in poverty measurement. 2006. Available from: http://www.ibge.gov.br/ poverty/pdf/rio_group_compendium.pdf (Accessed 8 February 2011)

101. Nguyen CT, Couture M-C, Alvarado BE, Zunzunegui M-V. Life course socioeconomic disadvantage and cognitive function among the elderly population of seven capitals in Latin America and the Caribbean. J Aging Health. 2008;20:347-62. 
102. Blazer DG, Sachs-Ericsson N, Hybels CF. Perceptions of unmet basic needs as a predictor of mortality among community-dwelling older adults. Am J Public Health. 2005;95:299-304.

103. Blazer DG, Sachs-Ericsson N, Hybels CF. Perceptions of unmet basic needs as a predictor of depressive symptoms among community-dwelling older adults. J Gerontol A Biol Sci Med Sci. 2007;62:191-5.

104. Wilkinson RG. Ourselves and others - For better or worse: social vulnerability and inequality. In: Marmot M, Wilkinson RG, Editors. Social determinants of health. Oxford (UK): Oxford University Press; 2006. p. 341-358. 